\title{
The work of health visitors and school nurses with children with psychological and behavioural problems
}

(Short title: Psychological workload of health visitors and school nurses)

Philip Wilson DPhil MRCP MRCPCH FRCGP

General practitioner and senior research fellow.

Section of general practice and primary care,

University of Glasgow, 1 Horselethill Rd, Glasgow, G12 9LX. email:

p.wilson@clinmed.gla.ac.uk telephone: 01416326310

Judy Furnivall, MA BSc MSc

Lecturer (advice and consultancy), Scottish Institute for Residential Child Care,

University of Strathclyde, 76 Southbrae Drive, Glasgow G13 1PP. email:

judith.furnivall@strath.ac.uk telephone: 0141-950-3571

Rosaline S. Barbour MA PhD,

Professor of health and social care, School of Nursing and Midwifery, University of

Dundee, 11 Airlie Place, Dundee DD1 4HJ email: r.barbour@dundee.ac.ulk telephone:

01382388557

Graham Connelly BEd, MEd, EdD, CPsychol, Senior Lecturer, Department of Educational and Professional Studies, University of Strathclyde, 76 Southbrae Drive, Glasgow G13 1PP. email: g.connelly@strath.ac.uk telephone: 0141-950-3131

Graham Bryce MB ChB FRCPsych 
Consultant psychiatrist for children and young people, NHS Greater Glasgow and Clyde, 62 Templeton Street, Glasgow G40 1DW email: graham.bryce@yorkhill.scot.nhs.uk telephone: 01412777400

Louise Phin BSc Assistant psychologist, Department of Child and Family Psychiatry, Royal Hospital for Sick Children, Glasgow G3 8SJ. Email louisephin@hotmail.com : telephone: 01412019239

Anna Stallard MA. MAppSci. PhD

Consultant clinical psychologist (adolescents), Direct Access, NHS Greater Glasgow and Clyde, Old Sandy road Clinic, 12 Sandy Road, Glasgow G11 6HE email: Anna.Stallard@glacomen.scot.nhs.uk telephone: 01412329215

\section{ACKNOWLEDGEMENTS}

The survey was funded by the Scottish Needs Assessment Programme. Financial support for the analysis came from HeadsUpScotland, the National Project for Children and Young People's Mental Health. Philip Wilson's research career award in infant mental health is funded by the Scottish Executive Health Department Chief Scientist Office. Irene Stirling, Information Services Librarian, Jordanhill Library, University of Strathclyde helped with literature searches. Linda Wallis provided guidance on current policy issues.

The research team conducted this work independently of the funders, and the views expressed here are not necessarily those of the funding organisations. 
Abstract:

Aim

This paper is a report of a study to describe the workload of health visitors and school nurses in relation to children and young people with psychological, emotional or behavioural problems, and to identify perceived challenges, obstacles and sources of satisfaction associated with this aspect of their work.

\section{Background}

There is little published information on the work done by non-specialist community nurses with children and young people who have psychological, emotional and behavioural problems.

\section{Method}

We analysed data from a survey of 1049 Scottish professionals working with children and young people. Data included quantitative responses and free text describing the cases seen by respondents. Responses from a sub-sample of 71 health visitors and 100 school nurses were analysed using a combination of descriptive statistics and analysis of themes emerging from the text.

\section{Findings}

Although community-based nurses saw a relatively small number of children with psychological, emotional or behavioural problems each week, dealing with these problems took up a disproportionate amount of time. The commonest types of problem were self-harm, externalising behaviours and family difficulties. Few respondents had received specific training in child and adolescent mental health but most expressed a wish to receive such training.

\section{Conclusion}

The work of health visitors and school nurses in caring for children with mental health problems is substantial and important. Development of their public health role should not be at the expense of this important contribution. There is a need for rigorous evaluation of nursing mental health interventions among children and young people.

\section{KEYWORDS}

Health visitors, school nurses, questionnaire, empirical research report, children, psychological problems, behavioural problems 


\section{SUMMARY STATEMENT}

\section{What is already known on this topic}

- There is some evidence that input by community-based nurses can have a major impact on the mental well-being of children and young people

- Policy documents acknowledge the important role of both school nurses and health visitors, who are responsible for providing professional support for children and young people with psychological and behavioural problems.

- Detailed information on the precise nature of school nurses' and health visitors' involvement - workload, demands, and satisfaction - is not available.

\section{'What this study adds'}

- Health visitors and school nurses have substantial, but different, mental health caseloads

- Nurses reported that a lack of training and support limited their ability to provide good quality care to children and young people

- Self-harm, externalising behaviours and family difficulties were the commonest problems described. 


\section{INTRODUCTION}

The mental health of children and young people is crucially important to the wellbeing of society and it has recently received considerable attention from policymakers. In 2000, the Scottish Executive Health Department commissioned a needs assessment of child and adolescent mental health - the SNAP CAMH process. The final report of this substantial needs assessment process was published in 2003 (Scottish Needs Assessment Programme 2003) and its findings have had a major influence on policy in Scotland.

A wide range of professionals who did not have mental health as the central component of their work but who worked routinely with children and young people were approached as part of the needs assessment process. The SNAP team approached health visitors (HVs), school nurses (SNs), general practitioners (GPs), paediatricians, social workers, residential care workers, foster carers, teachers, voluntary sector staff and workers in the youth justice system. A general report on the professional survey has recently been published (SNAP Research Group 2006) but here we report in more detail on the responses of community-based nurses who make a major contribution to the mental wellbeing of children and young people.

\section{BACKGROUND}

In many parts of the developed world, school nurses and health visitors provide services for children and young people with, or at risk of, psychological, emotional or mental health problems as part of their role (Hewitt et al. 1990; Aurelius \& Nordberg 1994; Ellefsen 2002; Kearney et al 2000; Olds 2002; Hootman et al 2002; Sourander et al. 
2004). In order to identify research papers that provided information on the scope of such work and levels of involvement, we carried out a literature search.

We searched CINAHL, PsychoInfo, Medline, Embase, the Australian Education Index, ASSIA, ERIC, CSA Social Services Abstracts, ChildData, Science Direct, CommunityWise and SCIE Social Care Online using the search strategy: ("school nurs*" or "health visit*" or "community nurs*" or "community health nurs*") AND ("child*" or "pupil*" or "parent*" or "adolescent*" or "teen*") AND ("mental health" or "psychiatr*" or "psychol* or "behav*"). A total of 2835 references were retrieved. After elimination of opinion and educational articles and material irrelevant to the area of the work of school nurses and health visitors in the field of the mental health of children and young people, fewer than 60 articles remained.

\section{The changing policy context}

In the last decade both the school nursing and health visiting professions have been expected to adopt a stronger public health approach (Department of Health.1999; Scottish Executive Health Department 2001; Hall \& Elliman 2003; DeBell 2006). This has shifted the emphasis from routine surveillance and screening towards health promotion work. For school nurses this implies more child and adolescent mental health promotion and effective targeting of resources towards vulnerable children. For health visitors the focus is on providing an enhanced service to those families at particular risk of developing problems. Although the role of both school nurses and health visitors is in transition there remains uncertainty about exactly what is required of them in dealing with children and young people in emotional distress. The expectation of their public 
health role leads to a focus on preventive work, health education and early identification of problems but many practitioners regularly have to deal with complex psychological or behavioural problems without support from appropriately qualified mental health professionals (Thomas et al 1982; Leighton et al 2003).

\section{Mental health workload}

In one focus group study of school nurses exploring the functioning of drop-in clinics in schools (Allen 2004), nurses reported that the majority of young people presented with emotional or psychological difficulties such as stress, depression, self harm or eating disorders. One primary care trust undertook a consultation with 17 school nurses to identify their mental health training needs (Mitchell et al 2004).All of the nurses identified a high incidence of emotional and behavioural difficulties in the children who consulted them though the pattern of problems differed between primary school and secondary school pupils. The nurses identified six areas for which they would have liked further training: emotional problems; psychotic symptoms; family/relationship difficulties; psychosomatic symptoms; challenging behaviour; and self harm and risk taking behaviour. Another study of 12 school nurses (Leighton et al 2003) identified problems at home as the most common set of difficulties, followed by school based problems, behavioural difficulties and emotional problems. Anxiety, depression and major mental illness were less common although respondents did state that even children in primary schools were presenting with anxiety and depression. In a study of a specific school nurse-led mental health clinic (Chipman \& Gooch 2003) out of 28 cases the problems were classified as behavioural (15); anxiety (7); psychosocial (3); parent-child 
conflict (3); and school refusal (3). A study of a school based health centre in the USA used by up to 2000 young people a year reported that $17 \%$ of consultations were for emotional or psychological difficulties and that the rate of mental health consultations had quadrupled within five years of the centre's inception. A range of clinicians worked in this centre and not all consultations were with nursing professionals.

Health visitors have always been a source of advice for parents about common behavioural difficulties. One study (Hewitt et al 1989) showed that $31 \%$ of nine month old infants and $48 \%$ of two year old toddlers displayed at least one problematic behaviour. Another study of 53 health visitors in South Glamorgan (Thomas et al 1982) reported that health visitors regularly worked with families where young children were displaying a range of problems including eating, sleeping and hyperactivity difficulties. These problems were considered to be seriously disruptive of family life, particularly sleeping difficulties and hyperactivity but clinical records of a sub-sample of these health visitors showed that there was little improvement in behaviour during the course of one year. Health visitors are important in the identification of mental health problems $-\mathbf{a}$ study exploring pathways to a mental health service found that $82 \%$ of the parents of children under the age of seven had discussed their problems with health visitors (Godfrey 1995). Several parents commented that there had been no-one else with whom they could have discussed their problems.

A study in the UK showed that health visitors accurately recognised certain emotionally damaging family dynamics such as negative treatment by parents of one child within the 
sibling group although they experienced frustration at their failure to obtain professional help in such situations from either social services or mental health services (Rushton 2005). A Swedish study (Aurelius \& Nordberg 1994) demonstrated that home visiting nurses are able to make valid assessments of the psychological risk of infants at neonatal visits. A further example of the value of assessment by health visitors is that they first identify and refer most children with autism spectrum disorders (Chakrabarti \& Fombonne 2005)

Despite the high prevalence of psychological problems (Egger \& Angold 2006; Meltzer et al. 2003) children, adolescents and their families are often reluctant to seek help for psychological problems (Samargia et al 2006). Studies that have sought to elicit the views of service users and colleagues (O'Luanaigh 2002; Sourander et al 2004; Baudier \& Pallais-Baudier 2005) nevertheless identified high levels of satisfaction and suggested that health visitors and school nurses are perceived as reliable, available and non stigmatising. Furthermore, families prefer to seek help for psychological problems among their children from services based close to home (Sourander et al 2004). Since members of these two professional groups are likely to be the first point of contact for many children and young people with emotional or behavioural difficulties and can also have ongoing contact, school nursing and health visiting can be viewed as occupying key positions in relation to child and adolescent mental health.

\section{Impact on children's mental health}


There is substantial evidence that community-based nurses can have a major impact on the mental wellbeing of children and young people. For example, Olds et al. (1998) reported a 15 year follow up of a randomised trial of intensive perinatal home visitation programmes to high risk families in the USA. Compared with controls, young people in the intervention group had fewer instances of running away, fewer arrests, convictions and violations of probation, fewer lifetime sex partners, smoked fewer cigarettes and consumed less alcohol. Their parents also reported that their children had fewer behavioural problems related to use of alcohol and other drugs. A further trial using the same intervention demonstrated that much stronger effects were obtained when nurses delivered the visitation programme nurses than when it was delivered by lay home visitors (Olds et al. 2002), possibly as a result of greater emphasis by nurses on physical health and parenting advice (Korfmacher et al. 1999). In a multi-centre trial in the UK, health visitors trained in the Family Partnership Model provided weekly home visits from six months antenatally to 12 months postnatally in the intervention group. At 12 months, differences favouring the home-visited group were observed on an independent assessment of maternal sensitivity and infant co-operativeness (Barlow et al. 2007). The Solihull approach to infant mental health, in which health visitors play a pivotal role, has been shown to reduce parenting stress and health visitor ratings of the severity of behavioural problems (Milford et al. 2006).

Other studies have demonstrated the potential for school nurses to provide a helpful service to young people who are experiencing emotional and social difficulties. An integrative review of the literature on the impact of mental health needs on children's 
experience of school (DeSocio \& Hootman 2004) concluded that the school nurse was well placed to identify emotional problems and provide early intervention. A Scandinavian study that explored the role of school health services on bullying (Borup 2007) concluded that school children who are bullied benefit from discussing the situation with the school nurse. A study evaluating the impact of drop-in clinics run by school nurses (Kay 2006) reported that interpersonal problems and emotional difficulties were the most common reasons given by pupils for attending the service. The service was perceived positively and $92 \%$ of young people who had attended felt that the drop-in clinic was important. Another clinic set up to deal specifically with emotional and mental health needs reported high satisfaction from pupils, families and education colleagues (Chipman \& Gooch 2003). Evaluation of a nurse-led project designed to address challenging behaviour (Buckland et al 2005) showed that with sufficient time, training and competencies it was feasible for school nurses to provide helpful interventions to families and children. Reductions in anxiety and depression were reported in children when school nurses delivered the cognitive-behavioural FRIENDS programme (Lomas 2007)

\title{
THE STUDY
}

\author{
Aims \\ The aims of the study were to describe the workload of HVs and SNs in relation to \\ children and young people with psychological, emotional or behavioural problems, and to \\ identify problems and sources of satisfaction associated with this aspect of their work.
}




\section{Design}

The study draws on responses from 71 health visitors and 100 school nurses to a selfcompletion questionnaire which collected data from a total of 1049 professionals employed in a wide range of roles throughout Scotland (SNAP Research Group 2006).

\section{Participants}

Respondents included school nurses and health visitors, with which this paper is concerned. During 2002 and 2003, questionnaires (Questionnaire A www.headsupscotland.co.uk/snap.html) were distributed to school nurses and health visitors throughout Scotland.

The SNAP survey group was not able to identify a nationally held list of HVs. Because of major time constraints and concerns about compromising GP response rates, a pragmatic decision was made to ask half the 280 GPs who were being surveyed (137 - 49\% - of whom replied) to pass a questionnaire on to one HV colleague. One consequence of this approach is that health visitors who are not attached to general practices (a minority in Scotland) are not represented in the survey. A total of 71 HVs responded from 140 questionnaires sent to GPs. The minimum response rate is therefore $51 \%$, but could have been substantially higher than this, since it is unlikely that all 140 questionnaires were passed on by GPs.

The Scottish national database of school nursing services was used to identify a senior nurse in each area, who was asked to distribute a specified number of questionnaires to a 
designated sample of SNs. A total of 230 questionnaires were distributed, and 100 were received at the survey office. Again the crude response rate of $43 \%$ is likely to underestimate the true figure since it is not known how many questionnaires were received.

\section{Ethical considerations}

The survey was completed before new UK research governance procedures introduced the requirement to obtain ethics permission for studies of healthcare professionals. Additionally, prior to the survey, we consulted the Glasgow Royal Hospital for Sick Children research ethics committee chair, who assured us that no ethics submission was required. The covering letter for the questionnaire reassured potential respondents that their responses would not be published in any form which could allow identification of individuals, and informed them that responses would be published in scientific journals as well as in the SNAP reports. The questionnaires were returned without any identifiers, and the mailing lists were deleted after data collection, so it was not possible to contact respondents again once new UK research ethics regulations were introduced in April 2003. The lead author of this paper confirmed with the Chair of his local university ethics committee in January 2004 that analysis and publication of data from the surveys would be ethically acceptable.

\section{Data collection}

Questionnaires elicited both restricted (quantitative) and free-text responses. Detailed information was collected on workload, client group, frequency of contact, nature of problems involved and length of time spent dealing with children and young people with 
psychological, emotional or behavioural problems. The free text sections (discussed below in more depth) invited respondents to comment on their most recent; most worrying; and most satisfying cases.

\section{Rigour}

Questionnaires were developed over two months by two members of the SNAP CAMH core group, were modified after discussion within the core group and then piloted on a range of professionals, including two health visitors, before further group discussion and finalisation. Quantitative analysis relied on pre-defined codes and descriptive statistics were generated using Microsoft Excel software. The qualitative software package QSR N6 was used to assign codes to the free text sections of questionnaires and to facilitate data retrieval (see further discussion below). We were fortunate in that the multidisciplinary team was able to draw on the insights of members with a wide variety of professional and research backgrounds. This ensured that coding categories and interpretations of data excerpts were thoroughly interrogated and allowed us iteratively to develop a consensus coding frame. This was accomplished through regular team meetings. In the qualitative analysis process patterns were identified (utilizing demographic details collected) and particular attention was paid to contradictions and exceptions - both in the written responses and with regard to interpretations by members of the research team.

\section{Data analysis}

The survey data were entered into a Microsoft Access database to allow easy retrieval of 
quantitative data, and the data were 'cleaned' by the authors. Quantitative items are reported here in terms of descriptive statistics only.

Free-text data from the Microsoft Access database were imported into the qualitative software QSR N6 using command files. This method allowed the quantitative data to be used automatically to code relevant segments of text - for example all free-text responses from a (1) female (2) school nurse working with (3) children aged 11-18 would have all three relevant codes attached.. The coding frame for analysing qualitative data was developed iteratively with revisions and refinements being made at a series of team meetings. This allowed us to capitalize on the diversity of the team as a resource in the analysis (Barbour 2003). The research team comprised a wide range of professionals working with children as well as a social scientist. Patterning in the data was systematically interrogated with data retrieval being aided by the use of the software package N6. Whilst codes used included descriptive 'a priori' (Kelle 1997) problembased codes, and standard diagnostic terms (for example autism or attentiondeficit/hyperactivity disorder) other codes were developed through identification of less precise but frequently-employed descriptions, which were employed as 'working definitions' by the professionals involved. These included the use of terms such as selfinjurious behaviour, suicide or attempted suicide, suicidal ideation, overdoses and self abuse - all of which were coded under the broad heading of 'self-harm'. For the analysis reported in this paper, some of the problem categories were linked - for example, the broad code of 'externalising behaviours' included truancy, running away, conduct problems and oppositionality. Other respondent-generated concepts informed the 
development of 'in-vivo' codes (Kelle 1997), such as 'nothing happened'; 'too little too late' - often relating to expressing frustration or satisfaction.

\section{RESULTS}

Responses were received from $71 \mathrm{HVs}$ and $100 \mathrm{SNs}$. One respondent in a remote rural area held combined $\mathrm{HV} / \mathrm{SN}$ posts, and so there were 170 analysable responses in total. Three of the school nurses and two of the health visitors were male.

\section{Workload}

Sixty-seven (96\%) health visitors worked with children aged under five years, compared with $85(86 \%)$ school nurses. Nineteen (27\%) health visitors and $98(99 \%)$ school nurses worked with children over five years of age. Most $(84 / 98,86 \%)$ of the school nurses appeared to work with children attending both primary (4-11 years) and secondary schools (11-17).

The total number of children seen each week varied fairly widely between respondents. More than half $(37 / 70,53 \%)$ of the health visitors saw $21-50$ children weekly while almost half $(46 / 99,46 \%)$ of the school nurses saw 50-99 children each week. Five health visitors and four school nurses working in specialist settings saw fewer than six children each week.

Table 1 describes the caseload of emotional, behavioural and psychological problems dealt with by respondents. A caseload of more than 10 children with psychological, emotional or behavioural problems was reported by $34 \%$ of HVs and $37 \%$ of SNs and 
one in five members of each professional group were seeing more than three such children in the course of one week.

Table 2 shows the reported time spent working with emotional, behavioural and psychological problems among children and young people. This work was shown to be particularly time-consuming for HVs, with $20 \%$ spending four or more hours per week with children in relation to this range of problems.

\section{Types of problems dealt with by respondents}

Three questions elicited free-text responses as follows:

- Thinking about the last time you dealt with a child or teenager with mental health, emotional or behavioural problems, what was the problem?

- Please think about the most worrying case of mental health, emotional or behavioural difficulties in a child or adolescent you have dealt with within the past three years. What was the problem?

- Now thinking about the management of a case of mental health, emotional or behavioural difficulties over the past three years which gave you most satisfaction, what was the problem?

For each of these questions, respondents were asked what they did, what they would like to have done and what the barriers were to achieving the outcome they would have liked (in the example of the case giving most satisfaction, the last of these items was replaced with 'why did you find the management of the case so satisfactory').These questions about cases were not completed by all respondents. Non-completion rates by HVs were 
$2 / 71(3 \%)$ for the last case, $14 / 71(20 \%)$ for the most worrying case and $18 / 71(25 \%)$ for the most satisfying case. The corresponding figures for SNs are 7/100 (7\%), 20/100 (20\%) and 35/100 (35\%). Furthermore five HVs (7\%) and three SNs (3\%) specifically denied having had any worrying cases in the past three years while eight HVs (11\%) and 15 SNs (15\%) denied having had any satisfying cases:

"None of the children I am involved with ... have had a satisfactory outcome so far" (School Nurse, SCN161)

It proved possible to obtain information on the types of problem seen by the nurses in almost all the remaining responses, although a total of 23 questions were answered in general terms rather than in terms of a specific case - and these responses are not included in the analysis.

Figures 1 and 2 illustrate the caseload of HVs and SNs. Chronic physical illness featured in three school nurse accounts of their last case, four of their most worrying cases and three of their most satisfying cases. In contrast chronic illness only arose in one 'most satisfying' health visitor case. It should be noted that many of the cases described had more than one problem.

\section{Barriers to achieving desired outcomes}

The most commonly reported barrier for school nurses and health visitors related to difficulties both groups experienced in making referrals, difficulties or delays they had in accessing specialist services, or a lack of specialist support available locally. Barriers of 
this kind were reported by $22 / 100(22 \%)$ of the school nurses and $28 / 71(39 \%)$ of the health visitors.

"I believe this parent has not received help she wished... I wonder if school attempt to put off parents requesting educational psychology due to lack of resources and volume of referrals they have for psychology" (Health Visitor HV0068).

A second important barrier reported by 20/100 (20\%) of the school nurses, but only six ( $9 \%)$ of the health visitors was the effects of lack of time and a heavy workload.

Difficulties arising from a lack of co-operation by the child or parents were mentioned by $14(20 \%)$ of the health visitors and $13(13 \%)$ of the school nurses.

It is a matter of great concern that the nurses who described difficulties in accessing professional support and specialist services were also dealing with children exhibiting very serious emotional or behavioural difficulties. For example, of the 22 school nurses who reported access or referral difficulties, 20 described most worrying cases which included self-harm, aggressive behaviour, abuse and depression/suicidal feelings. The frustration and powerlessness of recognising a worrying case but not having easy or swift access to specialist services comes across graphically in responses.

"No appointment offered, required formal referral from GP. The girl attended $A \& E$ several times - self-harm - eventually admitted to special unit” (school nurse SCN 007).

\section{Training}


An important difference between school nurses and health visitors was the extent to which they felt ill-prepared for their work through lack of confidence, inexperience, or as a result of not having the appropriate knowledge or training to support children or their families directly themselves. This concern was reported by 17/100 (17\%) of school nurses but only five $(7 \%)$ of the health visitors.

"Lack of my training needs to deal more appropriately with situation, I read literature etc. but this does not compensate for lack of training within mental health for children/young people” (school nurse SCN190).

Only 17/71 (24\%) health visitors and 30/100 (30\%) school nurses reported ever having had any specific training in mental health problems among children and young people. In contrast, 58/66 health visitors (88\%) and 89/95 (94\%) school nurses expressed a desire to receive training in the mental health of children and young people.

\section{Impact on respondents}

School nurses in particular expressed a great deal of uncertainty about their practice. As well as being concerned at their perceived lack of knowledge and skill many felt overwhelmed by the number and complexity of the cases they faced: "Many young people identified on a weekly basis at pupil support group meetings. I can only work with a few and often feel frustration that there are so many" (School Nurse SCN131)

Twenty eight (28\%) of the 100 school nurses explicitly mentioned a lack of their own time as impeding their capacity to provide a proper service to young people. A similar proportion were frustrated at their inability to access external services for young people: 
"There should be a service for these young people who have been abused and need immediate help. I felt a sense of failure that once a young person had the confidence to speak out, nothing happened" (School Nurse SCN129).Several respondents also wanted direct access themselves to a mental health professional for advice and support in dealing with these children.

Health visitors expressed less uncertainty overall than school nurses and clearly felt competent in working with parents who were experiencing sleeping difficulties or common behavioural problems with their pre-school children. The cases that caused them greatest worry, however, were those which challenged their normal work boundaries, in particular school age children exhibiting very disturbing behaviour such as self harm, violence, substance misuse or fire setting. Health visitors' responses to these cases were similar to those of school nurses. They too expressed a wish not just for training but structured access to support their direct work with children and families: "Perhaps meetings with psychology in order that we can bring cases that can be managed at HV level and discuss strategies to help this family and child" (Health Visitor HV0068).

Despite the frustration and uncertainty expressed by both groups of nurses 35/71 (49\%) health visitors and 37/100 (37\%) school nurses identified good outcomes for young people as a source of satisfaction in at least some of their cases.

\section{DISCUSSION}

\section{Study limitations}


There are several limitations to our methodology, largely dictated by pragmatic requirements to maximise response rate in the very limited time available for the survey. We received responses to about half of the questionnaires distributed, but we do not know the number of nurses who actually received the questionnaire. We acknowledge that our strategy of approaching health visitors through the general practices to which they were attached was not ideal. If there had been more time available for the survey, liaison with health board directors of nursing would have helped to ensure more comprehensive and representative coverage. Nevertheless respondents provided rich data, and many provided detailed accounts of the problems they face in their work with children and young people with psychological problems. The wide range of professionals surveyed allowed for detailed comparative analysis and the present paper, although reporting only on the replies from school nurses and health visitors, has been able to locate their responses within this wider context, which also provided insights into the various working environments throughout Scotland.

Non-completion of the questions about cases may have resulted from a range of factors. For pragmatic reasons, all questionnaires had the questions about the last case, most worrying case and most satisfying case in the same sequence, and it is possible that the lower completion rates for the later questions may have partly resulted from fatigue. Nevertheless, some respondents specifically denied having had any worrying cases and a greater number denied having had any satisfying cases and it is possible that respondents who left these questions unanswered may have shared these sentiments. 
Once a coding frame had been established, it proved relatively straightforward to assign diagnostic and other codes to the problems the respondents described. Externalising behaviours, broadly defined as those associated with defiance and aggression are, unsurprisingly, commonly seen by HVs, presumably when parents request help with behavioural problems in their young children. In the school setting, SNs are less likely to see externalising problems presented by young people themselves.

\section{Discussion of results}

Helping children and young people with emotional, behavioural and psychological problems is an important and substantial part of the work of both HVs and SNs. While UK community nursing policy for children has shifted from routine surveillance and screening towards a public health role (Department of Health.1999; Scottish Executive Health Department 2001; Hall \& Elliman 2003; DeBell 2006), the provision of care has had an ambiguous place within this public health discourse. This may have exacerbated the difficulties of practitioners dealing with complex problems without appropriate specialist support (Thomas et al 1982; Leighton et al 2003). The Scottish Framework for Nursing in Schools (Scottish Executive, 2003 page 35) starts to acknowledge the issue: "Nurses in schools are involved in supporting children with mental health needs at level 1 and, where appropriate, level 2 in the 4-tier framework for managing mental health services. They may also be involved in supporting children at level 3 and 4 as part of a tailored package of care under the direct supervision of specialist mental health services". Although the acknowledgement of the need for supervision of difficult cases is welcome, 
the statement still begs the question of where support and training for the less complex problems is to come from.

Although detailed and comprehensive reports on the work done by HVs and SNs with emotional, behavioural and psychological problems among children are lacking, our results are broadly in accord with the limited published literature (Allen 2004; Chipman \& Gooch 2003; Leighton et al 2003; Milford et al. 2006; Thomas et al. 1982). The case mix seen by HVs differs substantially from that of SNs and the existence of this de facto specialisation suggests that policies promoting unification (eg Scottish Executive Health Department 2001) may diminish the power of their distinctive contributions to the mental health and well-being of children and young people.

The extent to which respondents, and in particular school nurses, have to deal with selfharm is striking. Deliberate self-harm is highly prevalent among young people in Britain - a recent survey (Hawton et al. 2002) gave a prevalence of 6.9\% among 15-16 year olds. The recent National Self Harm Enquiry (Mental Health Foundation 2006) raises concerns about the impact on SNs of working with self harm. Among our sample of nurses there is also a perceived lack of confidence in working with children and young people with mental health problems, and a high level of desire for training and ongoing support. This lack of training and support was clearly a source of frustration and distress to many respondents, and the recent development of care pathways for school nurses (Roberts 2006) is encouraging. Nevertheless, the perceived isolation of school nurses and the lack of easily accessible services for onward referral gives cause for concern. 


\section{CONCLUSION}

We have demonstrated that HVs and SNs are regularly encountering and managing major mental health difficulties among children and young people. This finding presents a major policy dilemma. On the one hand the public health discourse encourages community-based nursing professionals to involve themselves in health promotion, prevention of problems and systemic approaches to public health issues. There is also an acknowledgement that they are well placed to identify and refer serious health problems. Our findings make clear that, over and above any public health role, our respondents were providing an important clinical service to children and young people.

Although the HVs and SNs who responded to our survey were willing to take on responsibility for such work, they reported that it raised important challenges particularly when it engaged them at the margins of their role descriptions and work boundaries. Although they were able to cite some good outcomes, they expressed considerable frustration and talked of the worry engendered by working with children and young people who were experiencing serious problems. In particular, the lack of training identified by both disciplines is worrying. There is a strong case (Rafferty 2000) for provision of both further mental health training to community-based nurses working with children and young people, and the provision of ongoing supervision and professional support from psychological services. 
The evidence base for the effectiveness of community nursing interventions to improve the health of children and young people is weak, particularly in relation to school nursing (Wainwright et al. 2000). There is a need to document further the nature and scope of these interventions, thus laying the groundwork for more rigorous evaluations.

\section{REFERENCES}

Allen, B. 2004, "Drop-in clinics in secondary schools: the perceptions and experiences of school nurses", Education and Health, vol. 22, no. 3, pp. 39-43.

Aurelius, G. \& Nordberg, L. 1994, "Home visiting to families with a newborn child", Scandinavian Journal of Primary Health Care, vol. 12, no. 2, pp. 106-113.

Barbour, R. S. 2003, "The newfound credibility of qualitative research? Tales of technical essentialism and co-option", Qualitative Health Research, vol. 13, no. 7, pp. 1019-1027.

Barlow, J., Davis, H., McIntosh, E., Jarrett, P., Mockford, C., \& Stewart-Brown, S. 2007, "Role of home visiting in improving parenting and health in families at risk of abuse and neglect: results of a multicentre randomised controlled trial and economic evaluation", Archives of Disease in Childhood, vol. 92, no. 3, pp. 229-233.

Borup, I. 2007, "Schoolchildren who are victims of bullying report benefit from health dialogues with the school nurse,", Health Education Journal, vol. 66, no. 1, pp. 58-67.

Buckland, L., Greaves, C., \& Rose, J. 2005, "New roles for school nurses: preventing exclusion", Community Practitioner, vol. 78, no. 1, pp. 16-19.

Chakrabarti, S. \& Fombonne, E. 2005, "Pervasive developmental disorders in preschool children: confirmation of high prevalence", American Journal of Psychiatry, vol. 162, no. 6, pp. 1133-1141.

Chipman, M. \& Gooch, P. 2003, "Community school nurses and mental health support: a service evaluation", Paediatric Nursing, vol. 15, no. 3, pp. 33-35.

Department of Health. 1999, Making a difference: strengthening the nursing, midwifery and health visitor contribution to health and healthcare., Department of Health, London.

Egger, H. L. \& Angold, A. 2006, "Common emotional and behavioral disorders in preschool children: presentation, nosology, and epidemiology", Journal of Child Psychology \& Psychiatry \& Allied Disciplines, vol. 47, no. 3-4, pp. 313-337. 
Ellefsen, B. 2002, "School nursing on Scotland and Norway compared.", Community Practitioner, vol. 75, no. 8, pp. 299-303.

Godfrey, J. M. 1995, "Pathways to a child mental health service", Child: Care, Health \& Development, vol. 21, no. 4, pp. 223-232.

Hall, D. M. B. \& Elliman, D. 2003, Health for all children Fourth Edition OUP, Oxford.

Hawton, K., Rodham, K., Evans, E., Weatherall, R. 2002, "Deliberate self harm in adolescents: self report survey in schools in England", BMJ, vol. 325, no. 7374, pp. 12071211.

Hewitt, K., Powell, I., \& Tait, V. 1989, "The behaviour of nine-month and two-year-olds as assessed by health visitors and parents", Health Visitor, vol. 62, no. 4, pp. 52-55.

Hewitt, K. E., Appleton, P., Douglas, J., Fundudis, T., \& Stevenson, J. 1990, "Pre-school. health visitor based services for pre-school children with behaviour problems", Health Visitor, vol. 63, no. 5, pp. 160-162.

Hootman, J., Houck, G. M., \& King, M. C. 2002, "A Program To Educate School Nurses about Mental Health Interventions", Journal of School Nursing, vol. 18, no. 4, pp. 191195.

Kay, C. M. 2006, "To what extent are school drop-in clinics meeting pupils' selfidentified health concerns?", Health Education Journal, vol. 65, no. 3, pp. 236-251.

Kearney, M. H., York, R., \& Deatrick, J. A. 2000, "Effects of home visits to vulnerable young families.", Journal of Nursing Scholarship, vol. 32, no. 4, pp. 369-376.

Kelle, U. 1997, "Theory building in qualitative research and computer programs for the management of textual data", Sociological Research Online

(http://www.socresonline/1/1/4.html), vol. 2.

Korfmacher, J., O'Brien, R., Hiatt, S., \& Olds, D. 1999, "Differences in program implementation between nurses and paraprofessionals providing home visits during pregnancy and infancy: a randomized trial", American Journal of Public Health, vol. 89, no. 12 , pp. 1847-1851.

Leighton, S., Worraker, A., \& Nolan, P. 2003, "School nurses and mental health, part 1", Mental Health Practice, vol. 7, no. 4, pp. 14-16.

Lomas, C. 2007, "Best friends", Nursing Times pp. 20-21.

Meltzer, H., Gatward, R., Goodman, R., \& Ford, T. 2003, "Mental health of children and adolescents in Great Britain", International Review of Psychiatry, vol. 15, no. 1-2, pp. 185-187. 
Mental Health Foundation 2006, Truth Hurts. National Enquiry into Self-Harm. Mental Health Foundation, London.

Milford, R., Kleve, L., Lea, J., \& Greenwood, R. 2006, "A pilot evaluation study of the Solihull Approach", Community Practitioner, vol. 79, no. 11, pp. 358-362.

Mitchell, G., Baptiste, L., \& Potel, D. 2004, "Developing links between school nursing and CAMHS", Nursing Times, vol. 100, no. 5, pp. 36-39.

O'Luanaigh, P. O. 2002, "Views held by service users and colleagues of health visitor provision,", Community Practitioner, vol. 75, no. 4, pp. 139-141.

Olds, D. L. 2002, "Prenatal and infancy home visiting by nurses: from randomized trials to community replication", Prevention Science, vol. 3, no. 3, pp. 153-172.

Olds, D. L., Robinson, J., O'Brien, R., Luckey, D. W., Pettitt, L. M., Henderson, C. R., Jr., Ng, R. K., Sheff, K. L., Korfmacher, J., Hiatt, S., \& Talmi, A. 2002, "Home visiting by paraprofessionals and by nurses: a randomized, controlled trial", Pediatrics, vol. 110, no. 3 , pp. 486-496.

Rafferty, M. A. 2000, "A conceptual model for clinical supervision in nursing and health visiting based upon Winnicott's (1960) theory of the parent-infant relationship", Journal of Psychiatric \& Mental Health Nursing, vol. 7, no. 2, pp. 153-161.

Roberts, B. 2006, "Development of a school nurse care pathway for self-harm", British Journal of School Nursing, vol. 1, no. 1, pp. 32-37.

Rushton, A. 2005, "Negative parental treatment of the singled-out child: responses to the problem by health visitors, social services departments and child and adolescent mental health services,", Clinical Child Psychology and Psychiatry, vol. 10, no. 3, pp. 413-428.

Samargia, L. A., Saewyc, E. M., \& Elliott, B. A. 2006, "Foregone mental health care and self-reported access barriers among adolescents", Journal of School Nursing, vol. 22, no. 1, pp. 17-24.

Scottish Executive Health Department 2001, Nursing for Health: A review of the contribution of nurses, midwives and health visitors to improving the public's health in Scotland Scottish Executive, Edinburgh.

Scottish Executive 2003. A Scottish Framework for Nursing in Schools. Scottish Executive, Edinburgh.

Scottish Needs Assessment Programme 2003, Needs assessment report on child and adolescent mental health. Final Report.

http://www.headsupscotland.co.uk/documents/SNAP1.pdf Public Health Institute of Scotland. 
SNAP Research Group 2006, Only connect: addressing the emotional needs of Scotland's children and young people: A report on the SNAP Child and Adolescent Mental Health Phase Two survey. http://www.headsupscotland.co.uk/snap.html NHS Health Scotland, Edinburgh.

Sourander, A., Santalahti, P., Haavisto, A., Piha, J., Ikaheimo, K., \& Helenius, H. 2004, "Have There Been Changes in Children's Psychiatric Symptoms and Mental Health Service Use? A 10-Year Comparison from Finland.", Journal of the American Academy of Child \& Adolescent Psychiatry, vol. 43, no. 9, pp. 1134-1145.

Thomas, J. A., Bidder, R. T., Hewitt, K., \& Gray, O. P. 1982, "Health visiting and preschool children with behavioural problems in the County of South Glamorgan: an exploratory study", Child: Care, Health \& Development, vol. 8, no. 2, pp. 93-103.

Wainwright, P., Thomas, J., Jones, M. 2000. Health promotion and the role of the school nurse: a systematic review. Journal of Advanced Nursing. vol 32 no. 5, pp. 1083-1091 


\begin{tabular}{|c|c|c|c|c|c|c|c|c|c|c|c|}
\hline & \multicolumn{6}{|c|}{$\begin{array}{l}\text { Total caseload of children with } \\
\text { psychological problems }\end{array}$} & \multicolumn{4}{|c|}{$\begin{array}{l}\text { Number of children with } \\
\text { psychological problems seen per } \\
\text { week }\end{array}$} \\
\hline & & $\begin{array}{l}\mathscr{0} \\
\text { Z }\end{array}$ & $\begin{array}{l}n \\
1 \\
-1\end{array}$ & $\begin{array}{l}\frac{0}{1} \\
6\end{array}$ & $\begin{array}{l}\text { กิ } \\
1 \\
=\end{array}$ & $\frac{0}{n}$ & $\stackrel{\circ}{\wedge}$ & $\bar{V}$ & $\stackrel{I}{I}$ & $\stackrel{n}{n}$ & $n$ \\
\hline \multirow{2}{*}{$\begin{array}{l}\text { Health } \\
\text { visitors } \\
\mathrm{N}=70 \\
\end{array}$} & $\mathrm{~N}$ & 5 & 29 & 12 & 11 & 8 & 5 & 26 & 31 & 8 & 5 \\
\hline & $\%$ & 7 & 41 & 17 & 16 & 11 & 7 & 37 & 44 & 11 & 7 \\
\hline \multirow{2}{*}{$\begin{array}{l}\text { School } \\
\text { nurses } \\
\mathrm{N}=93\end{array}$} & $\mathrm{~N}$ & 7 & 29 & 22 & 19 & 11 & 5 & 38 & 35 & 16 & 4 \\
\hline & $\%$ & 8 & 31 & 24 & 20 & 12 & 5 & 41 & 38 & 17 & 4 \\
\hline
\end{tabular}

Table 1. Respondents' caseloads of emotional, behavioural and psychological problems.

\begin{tabular}{|c|c|c|c|c|c|c|}
\hline & \multicolumn{5}{|c|}{$\begin{array}{l}\text { Hours per week spent working with children with } \\
\text { psychological problems }\end{array}$} \\
\hline & & $\overrightarrow{\mathrm{V}}$ & $\stackrel{\Upsilon}{-}$ & 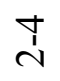 & $\stackrel{\infty}{\dot{j}}$ & $\stackrel{\infty}{\wedge}$ \\
\hline \multirow{2}{*}{$\begin{array}{l}\text { Health } \\
\text { visitors } \\
\mathrm{N}=68\end{array}$} & $\mathrm{~N}$ & 19 & 26 & 9 & 11 & 3 \\
\hline & $\%$ & 28 & 38 & 13 & 16 & 4 \\
\hline \multirow{2}{*}{$\begin{array}{l}\text { School } \\
\text { nurses } \\
\mathrm{N}=85\end{array}$} & $\mathrm{~N}$ & 29 & 28 & 18 & 8 & 2 \\
\hline & $\%$ & 34 & 33 & 21 & 9 & 2 \\
\hline
\end{tabular}

Table 2. Respondents' reports of time spent dealing with emotional, behavioural and psychological problems. 


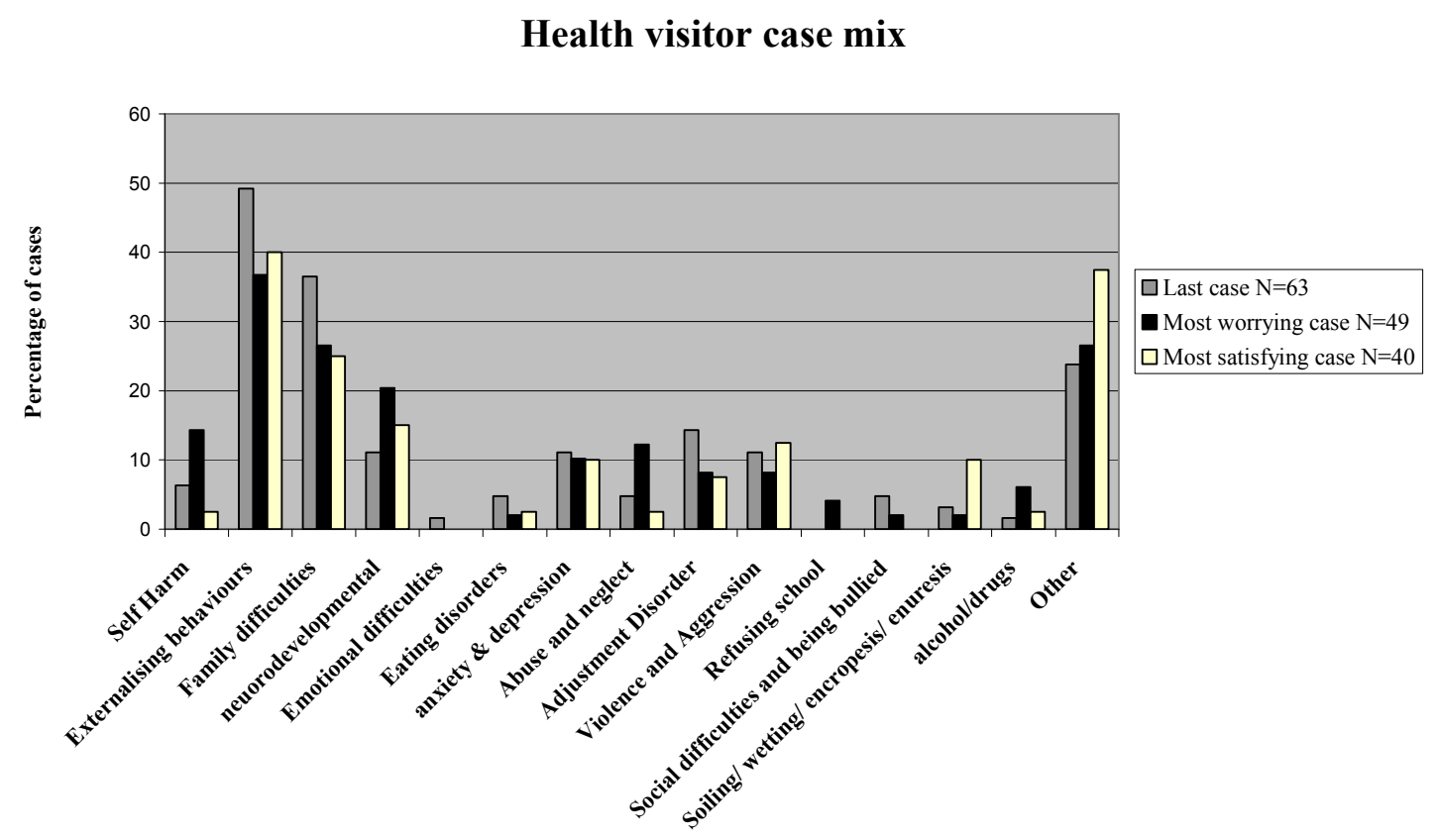

Figure 1. Health visitor cases. $N$ refers to the number of responses in which it proved possible to assign a diagnostic classification.

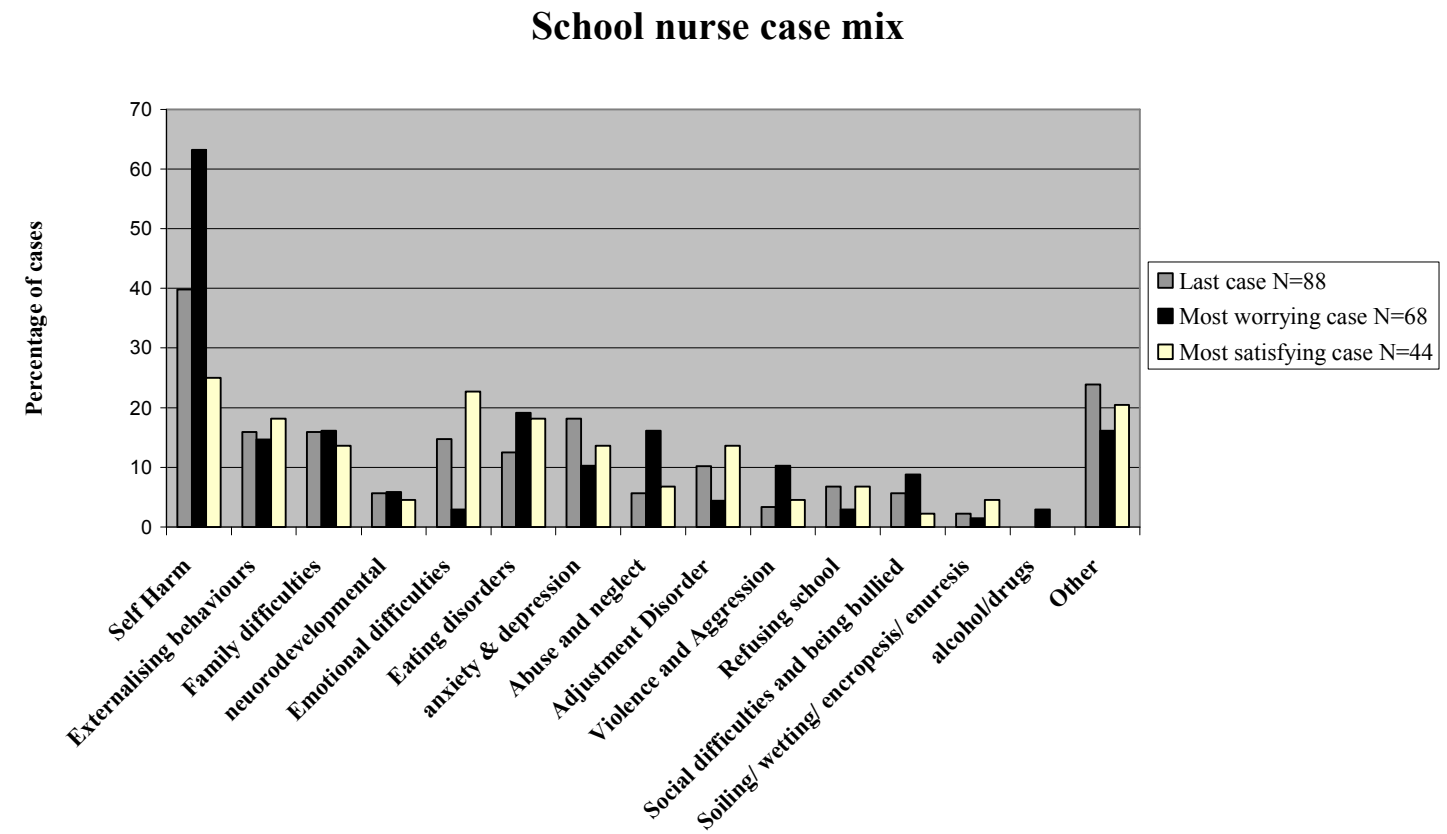

Figure 2. School nurse cases. $\mathrm{N}$ refers to the number of responses in which it proved possible to assign a diagnostic classification. 